\title{
REVIEW
}

\section{COMMUNICATION AND INTERPERSONAL SKILLS ENHANCEMENT IN MIDWIFERY: REVIEW}

\section{Zuzana Škodová}

Department of Midwifery, Jessenius Faculty of Medicine in Martin, Comenius University, Slovakia

Received February 26, 2016; Accepted March 21, 2016. Copyright: This is an open access article distributed under the terms of the Creative Commons Attribution International License (CC BY). http://creativecommons.org/licenses/by/4.0/

\begin{abstract}
Aim: The aim of this study is to analyze the available research evidence on the effectiveness of training methods used in communication and interpersonal skills enhancement in midwifery practice and study. Design: Review. Methods: A systematic search in SCOPUS and PubMed databases was performed, with the following selection criteria for studies: quantitative studies in English between the years 2006-2016, using the key words: communication enhancement, communication training, and midwifery in their abstract or title. Theoretical analyses of the problem and review articles were excluded. The search process resulted in the discovery of nine studies focusing on communication skills enhancement in midwifery. Results: All of the available studies confirmed positive effects on communication skills in general, particularly on self-confidence, selfawareness, subjective feelings of competency, and communication within the team. Roleplay with patient-actors proved to be more effective than patient simulators. Conclusion: Although positive effects of the communication training programs were reported in the articles reviewed, there was a high level of heterogeneity in the intervention methods, length and outcome measures used within the training programs. Research studies comparing the effectiveness of the different training methods, using objective outcome measures, and with good quality methodological background, are needed in this area in order to formulate clear recommendations for practice regarding effective interventions.
\end{abstract}

Keywords: communication, communication training, midwifery, midwifery students, effectiveness of education, review.

\section{Introduction}

One of the basic goals for nurses and midwives is to ensure effective communication with clients and their relatives. Healthcare professionals should also communicate effectively within the team, to provide continual safe and quality health care (Cassey, Wallis, 2011). Recently, the importance of effective interprofessional teamwork has been emphasized, with interprofessional communication as the essential competency of team cooperation. Active listening, communication to ensure common understanding of decisions, setting of shared goals, and sharing responsibilities are key factors providing a basis for effective teamwork (Solomon, Salfi, 2011). The ability to successfully negotiate with others, to clearly and succinctly argue a point of view, and group decision-making and negotiation are also an important part of high-quality interpersonal relationships in a professional environment (Warland, Smith, 2012).

Corresponding author: Zuzana Škodová, Department of Midwifery, Jessenius Faculty of Medicine in Martin, Comenius University, Malá Hora 5, Martin, Slovakia; e-mail: skodova@jfmed.uniba.sk
A significant number of adverse events in health care can be attributed to problems with the application of non-clinical skills such as communication, team cooperation or effective decision-making ability. Communication and interpersonal skills are an essential part of effective health care, significantly complementing technical and clinical skills (Hobgood et al., 2010).

Training in communication and interpersonal skills is commonly included in the educational process in nursing and midwifery. However, considerable diversity exists in the use of different techniques and educational approaches, and the effectiveness of such training programs is rarely explored. For instance, Beaubien and Baker (2004) in their review article point out that simulation training using roleplay or computerized simulators has become a highly popular technique for training in team cooperation as well as other interpersonal and communication skills, but there is a lack of studies comparing different types of simulation and their effectiveness. More research is needed to empirically assess outcomes in this area. 


\section{Aim}

The focus of this study is to analyze the available research evidence on the effectiveness of training methods used in communication and interpersonal skills enhancement among midwives and midwifery students.

\section{Methods}

\section{Eligibility criteria}

The following selection criteria were chosen based on the research problem: full-text articles, in English, and published in peer-reviewed journals. Conference papers, book chapters, and articles published in non peer-reviewed journals were excluded, as were theoretical analyses of the problem or review articles.

\section{Sources}

The Scopus and PubMed databases were searched to identify publications relevant to the aims of this study.

\section{Search}

A comprehensive literature search in titles and abstracts of articles was implemented based on the following key words: communication enhancement, communication training, and midwifery. The Search process resulted in the discovery of nine studies focusing on communication skills enhancement in midwifery.

\section{Study selection and data analyses}

The search process returned a total of 702 articles. 161 studies meeting the eligibility criteria were found on the Pubmed database, and 541 were found on the Scopus database. In the next stage, duplicate studies were excluded. Next, publications focusing on theoretical aspects of communication in midwifery, and articles focusing on skills other than communication-related skills (clinical or theoretical knowledge) were excluded. Studies aimed at training programs in populations other than midwifery or midwifery students were excluded as well. This step, based on a study of abstracts, reduced the total to 18 publications. Scheme 1 refers to the screening process stages and results.

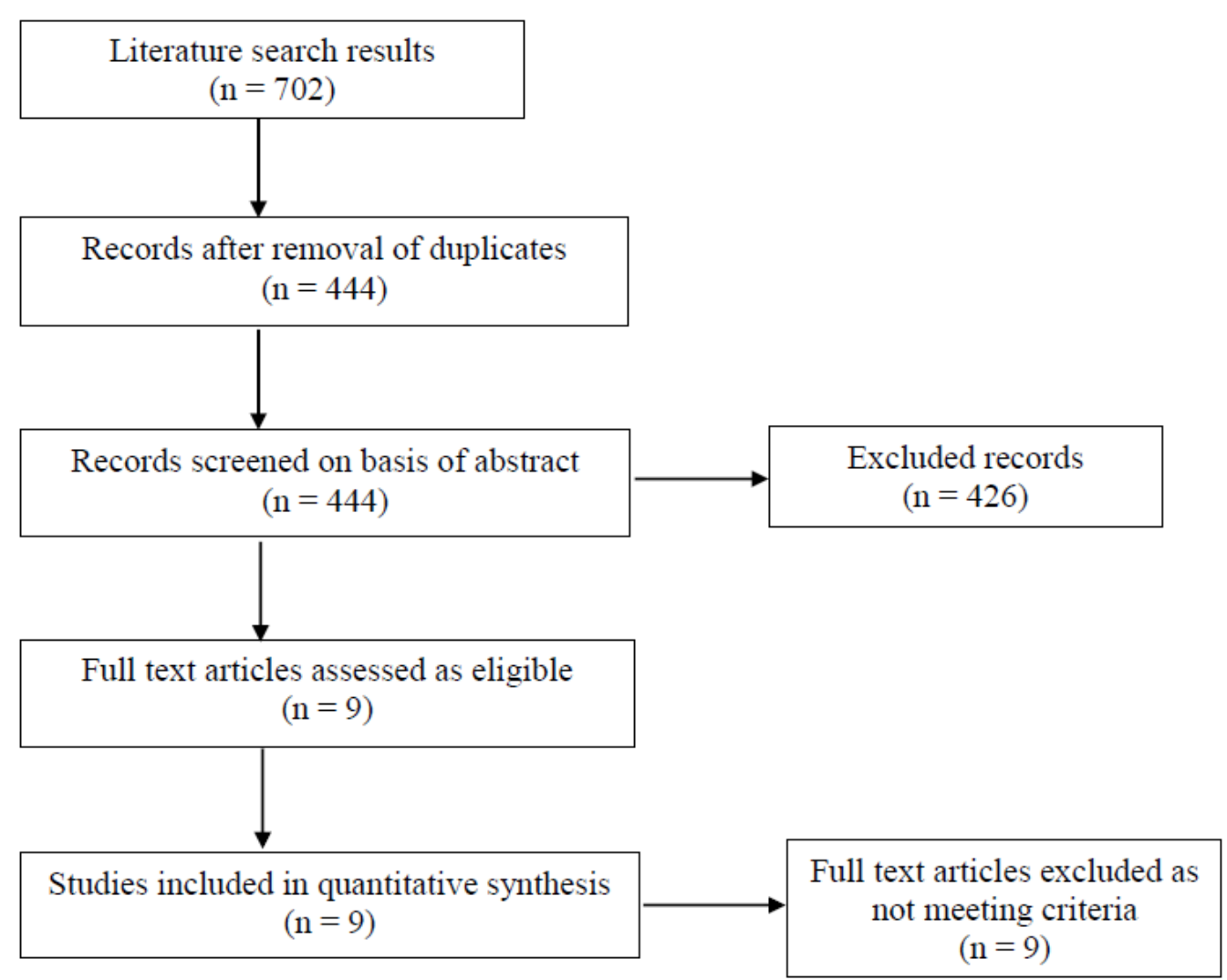

Scheme 1 Steps and results of the screening process - flow diagram 


\section{Results}

The screening process resulted in the selection of a total of nine relevant articles, consisting of empirical studies in which the impact of various training programs on communication skills among midwives, or midwifery students were reported (Scheme 1).

Methodological procedures in the studies selected for review

Midwifery and other healthcare professions featured in the research studies included in the review. In four studies, students of midwifery (in some cases combined with other healthcare students), were involved in training programs. In a study by McDonald et al. (2012) both midwifery students and midwives participated, and the remaining four studies include midwives (in three cases together with obstetricians) in training programs (Table 1). Most of the studies selected subjective evaluation of outcome variables, especially communication or interpersonal skills. Only the study by Crofts et al. (2008) employed a more objective measure: assessment of emergency situations by patient-actors, whereby communication was one of the three evaluated factors. A research study by Solomon and Salfi (2011) used the standardized Interpersonal Education Perception Scale (IEPS) in combination with subjective evaluation of the training program. The IEPS consists of four subscales, in which competence and autonomy, perceived need for cooperation, perceptions of actual cooperation, and understanding others' values are evaluated (Table 1). The duration of the intervention programs implemented in research studies was highly variable: from one three-hour session, and one or two-days' training, to projects lasting several months. A quasi-experimental pre-test - posttest research design (five studies) or ex post facto design (four studies) were used in the research articles included in the review. None of the reviewed studies with quasi-experimental design involved a control group in its research protocol (Table 1).

Table 1 Results of the review: description of methodological procedures used in studies selected for review

\begin{tabular}{|c|c|c|c|c|}
\hline Authors, year & Participants & Measures of outcome variables & Study design & $\begin{array}{l}\text { Length of the } \\
\text { intervention } \\
\text { program }\end{array}$ \\
\hline Catling et al., 2015 & $\begin{array}{l}71 \text { midwifery } \\
\text { students }\end{array}$ & $\begin{array}{l}\text { subjective evaluation by students }- \\
\text { open-ended questions survey }\end{array}$ & quasi experimental & 2 days project \\
\hline Parrat et al., 2014 & $\begin{array}{l}24 \text { midwifery } \\
\text { students }\end{array}$ & $\begin{array}{l}\text { online survey - subjective evaluation of } \\
\text { program effectiveness by students }\end{array}$ & ex post facto & $\begin{array}{l}2 \text { team-based } \\
\text { assignments over } \\
\text { the } 15 \text { weeks } \\
\text { period }\end{array}$ \\
\hline Monod et al., 2014 & $\begin{array}{l}51 \text { midwifes and } \\
102 \text { obstetricians }\end{array}$ & $\begin{array}{l}\text { subjective evaluation of program } \\
\text { effectiveness - on Likert scale }(1-6) \text {, in } \\
2 \text { time points: after the training and } 3 \\
\text { month follow up }\end{array}$ & ex post facto & $\begin{array}{l}6 \text { training courses } \\
\text { over the } 5 \text { months } \\
\text { period }\end{array}$ \\
\hline $\begin{array}{l}\text { Warland, Smith, } \\
2012\end{array}$ & $\begin{array}{l}12 \text { midwifery } \\
\text { students }\end{array}$ & $\begin{array}{l}\text { subjective evaluation by students - } \\
\text { questionnaire }\end{array}$ & ex post facto & $\begin{array}{l}7 \text { days briefing } \\
10 \text { days roleplays } \\
3 \quad \text { weeks } \\
\text { debriefing }\end{array}$ \\
\hline $\begin{array}{l}\text { McDonald et al., } \\
2012\end{array}$ & $\begin{array}{l}14 \text { midwifes and } \\
\text { students }\end{array}$ & $\begin{array}{l}\text { subjective evaluation }- \text { interviews and } \\
\text { research } \\
\text { intervention }\end{array}$ & ex post facto & $\begin{array}{l}6 \quad \text { one-day } \\
\text { workshops each } \\
\text { month }\end{array}$ \\
\hline $\begin{array}{l}\text { McLachlan et al., } \\
2011\end{array}$ & 25 midwifes & $\begin{array}{l}\text { subjective evaluation by midwifes - } \\
\text { questionnaire }\end{array}$ & & $\begin{array}{l}7 \text { sessions over } \\
\text { a } 6 \text { month period }\end{array}$ \\
\hline $\begin{array}{l}\text { Solomon, Salfi, } \\
2011\end{array}$ & $\begin{array}{l}96 \text { healthcare } \\
\text { students }(13 \text { in } \\
\text { midwifery) }\end{array}$ & $\begin{array}{l}\text { subjective measures of satisfaction, } \\
\text { focus groups and individual interviews, } \\
\text { The Interdisciplinary Education } \\
\text { Perception Scale (IEPS) }\end{array}$ & quasi experimental & 3 hours session \\
\hline Crofts et al., 2008 & $\begin{array}{l}95 \text { midwifes, } 45 \\
\text { doctors }\end{array}$ & $\begin{array}{l}\text { Objective - evaluation of handling the } \\
\text { emergency situation by patient actors }\end{array}$ & quasi experimental & $\begin{array}{l}\text { 1-day or 2-day } \\
\text { simulation course }\end{array}$ \\
\hline Birch et al., 2007 & $\begin{array}{l}36 \text { medical and } \\
\text { midwifery staff }\end{array}$ & $\begin{array}{l}\text { subjective evaluation - semi structured } \\
\text { interview }\end{array}$ & quasi experimental & 1 day training \\
\hline
\end{tabular}


Research findings in studies selected for review: effectiveness of methods aimed at communication or interpersonal skills enhancement

Only four studies included in the review focused primarily on communication or interpersonal skills development. Five of the research articles reported the results of training programs aimed primarily at developing clinical and/or theoretical knowledge and skills development in the area of midwifery, in particular, training in obstetrical emergency situations (Table 2).
Three main methods were used in intervention programs implemented in the reviewed studies: 1. simulation training through roleplay, 2. simulation training with computerized patient simulators, 3 . interactive communication training in small groups (Table 2).

All of the available studies confirmed a positive effect of the training on communication skills among participants (Table 2).

Table 2 Main findings of studies selected for review

\begin{tabular}{|c|c|c|}
\hline Authors, year & Methods used in the intervention program & $\begin{array}{l}\text { Findings - effectiveness of the intervention on } \\
\text { communication enhancement }\end{array}$ \\
\hline $\begin{array}{l}\text { Catling et al., } \\
2015\end{array}$ & $\begin{array}{l}\text { simulation workshops with role plays focused on } \\
\text { clinical midwifery skills }\end{array}$ & \\
\hline Parrat et al., 2014 & $\begin{array}{l}\text { team-based work with peer feedback focused on } \\
\text { theoretical knowledge }\end{array}$ & \\
\hline $\begin{array}{l}\text { Monod et al., } \\
2014\end{array}$ & $\begin{array}{l}\text { multi-professional, multidisciplinary } \\
\text { simulation training courses in emergency situations } \\
\text { in obstetrics }\end{array}$ & $\begin{array}{l}\text { improvement in team communication directly after } \\
\text { the training } \\
\text { difference between time point after the training and } \\
3 \text { month follow up was not statistically significant }\end{array}$ \\
\hline $\begin{array}{l}\text { Warland, Smith, } \\
2012\end{array}$ & $\begin{array}{l}\text { online roleplays with face-to-face debriefing aimed } \\
\text { on communication and collaboration }\end{array}$ & communication skills enhancement \\
\hline $\begin{array}{l}\text { McDonald et al., } \\
2012\end{array}$ & $\begin{array}{l}\text { interactive training of resilience in small groups } \\
\text { and pairs }\end{array}$ & $\begin{array}{l}\text { enhanced self-confidence, self-awareness, } \\
\text { communication and conflict resolution skills }\end{array}$ \\
\hline $\begin{array}{l}\text { McLachlan et al., } \\
2011\end{array}$ & $\begin{array}{l}\text { interactive small group workshops facilitated by } \\
\text { psychologist aimed on supporting women with } \\
\text { antenatal psychosocial problems }\end{array}$ & $\begin{array}{l}\text { increased communication skills } \\
\text { increased confidence and subjective feelings of } \\
\text { competency }\end{array}$ \\
\hline $\begin{array}{l}\text { Solomon, Salfi, } \\
2011\end{array}$ & $\begin{array}{l}\text { interview with a standardized patient focused on } \\
\text { inter-professional communication }\end{array}$ & $\begin{array}{l}\text { improved confidence in communication skills } \\
\text { increase in IEPS }\end{array}$ \\
\hline Crofts et al., 2008 & $\begin{array}{l}\text { comparison of simulation trainings in emergency } \\
\text { situations in obstetrics using simulators and patient } \\
\text { actors }\end{array}$ & $\begin{array}{l}\text { improved } \\
\text { higher improvement in group receiving training } \\
\text { with patient actors compared to computerized } \\
\text { simulators }\end{array}$ \\
\hline Birch et al., 2007 & $\begin{array}{l}\text { simulation training in emergency situations in } \\
\text { obstetrics (advanced human patient simulators) }\end{array}$ & improvement in communication skills \\
\hline
\end{tabular}

Improvement in communication and collaboration skills after a training program consisting of ten days of online roleplays, with comprehensive briefing and face-to-face debriefing, was reported in a study by Warland and Smith (2012). Online roleplays in this study were focused on two goals: understanding the role of midwives in infant immunization practice, and secondly, on improving skills in negotiating and debating, fostering teamwork and collaboration within a healthcare team.

Similarly, Catling et al. (2015) found developments in communication skills after a two-day simulation workshop, using both simulators and patient-actors. Five simulations based on antenatal, birth, postnatal and neonatal care scenarios were included in the program, in which students took turns playing the parts of a midwife, mother, and partner.

In an online survey focusing on the evaluation of innovative teaching methods, students rated the team-based work on academic assignments, with peer feedback proving an effective method (Parrat et al., 2014). Introducing peer evaluation into academic work helped to improve understanding of teamwork principles and the development of communication skills. One-day simulation training focusing on an emergency situation in obstetrical practice with the use of advanced human patient simulators by Birch et al. (2007) resulted in improvements in teamwork and communication skills among medical and midwifery staff. Three teaching methods were employed in this 
research: lecture-based teaching, simulation teaching, and a combination of both. Although the results were not statistically significant, simulation training achieved the best results in clinical skills, confidence, communication, and knowledge.

A study by Solomon and Salfi (2011) reported enhancement in communication, competence, autonomy, cooperation, and understanding others' values, following a one-day communication training program based on interviews with standardized patients.

A training program consisting of six one-day workshops over a six-month period in an article by McDonald et al. (2012) primarily focused on the development of resilience as one of the key interpersonal skills for coping with higher stress levels. Increased self-confidence, self-awareness, communication, and conflict resolution skills were reported by midwives and students after interactive training in small groups in this study.

A program of interactive small-group workshops, facilitated by a psychologist, increased confidence, subjective feelings of competency, and communication skills in participating midwives, according to a study by McLachlan et al. (2011).

A study by Monod et al. (2014) focusing on emergency situations in obstetrical practice found improvements in clinical skills and in team communication in midwives and obstetricians immediately after training. However, at the threemonth follow-up, statistically significant improvements were only apparent in clinical skills.

An intervention program focusing on obstetrical emergencies implemented by Crofts et al. (2008) using patient-actors and patient simulators resulted in greater improvement in communication skills in the group receiving training with patient-actors. This was the only study included in the review which used a combination of subjective evaluation of the program by participants and a more objective assessment of communication outcomes by patientactors who took part in the program.

\section{Discussion}

Articles included in the review might be divided into two groups. First, there were research studies focusing primarily on enhancement of practical and/or theoretical midwifery skills and knowledge, in which communication was one of a variety of factors evaluated at the end of the intervention program. Second, the review identified studies in which communication or interpersonal skills were the primary focus of the training program.
Most of the studies which primarily focused on communication or interpersonal skills enhancement involved more comprehensive training programs of greater length compared to studies focusing on clinical skills or knowledge. These programs also involved the use of intervention techniques, which are especially appropriate when targeting personal or behavioral changes, such as use of group dynamics, analysis and interpretation of interactions between participants in training, and interactive roleplays with evaluation and interpretation. Lin et al. (2004) reported that a number of literature sources assume that grouptraining in interpersonal skills, such as assertiveness, is more beneficial than individual training because the members of the group can practice assertiveness behavior within the group, with the same applying to interpersonal skills in general.

In a study by McDonald et al. (2012), collaborative, self-reflective, creative and therapeutic learning activities were involved in the training program. The interactive workshops implemented by McLachlan et al. (2011) included exploring the challenges and opportunities for woman-centered care, active listening, reflection of the factors which might encourage and discourage patients discussing sensitive issues with midwives, non-directive problem solving, and reflection on the individual communication styles of participants. The role of the leader of the training, or facilitator, is key to effective intervention. According to McDonald et al. (2012), the facilitator is required to monitor and adequately respond to the group atmosphere, and to pay special attention to the participants' well-being, self-esteem and sense of empowerment. They also emphasize the importance of keeping group members' disclosures confidential, and defining group guidelines as the key factors for successful group intervention.

However, based on the results of the review, it also appears that short-term training programs using roleplay had a positive effect on increasing the communication skills among midwives or midwifery students. In this context, it is interesting that a study by Crofts et al. (2008) found that roleplay training with patient-actors was more effective in communication skills enhancement than training using simulators. This is in line with the results of the review article by Beaubien, Baker (2004), who recommend using roleplay as a technique in developing attitudes to teamwork, due to its high psychological fidelity.

When evaluating the effectiveness of the intervention, the methodological background of the study is of high importance. Methodological 
limitations in studies selected for review include the absence of a control group in quasi-experimental studies, and the relatively small sample in some studies. Eccles et al. (2003) point out that there is evidence suggesting that the results of quasiexperimental studies without a control group may overestimate the effects of interventions. In this context, we might assume that the inclusion of a control group in a study ensures greater internal validity in the research and, thus, an increase in the relevance of the research findings for the purposes of practice and education. An additional methodological problem was identified: most of the research studies included in the review use subjective evaluation of improvements in communication skills, meaning that in almost all the studies participants in the intervention evaluated their own improvement. While such self-assessment has its value, it might not always correspond with more objective criteria. Only in the study by Crofts et al. (2008) did the authors use a more objective evaluation of an intervention program.

Thus methodological recommendations for future studies in this area might be as follows: the use of combinatory evaluation with both subjective and objective assessment (peer feedback, evaluation by an expert, etc.), and the inclusion of a control group in the research when using quasi-experimental research design.

\section{Conclusion}

Based on the screening process of articles relevant to the topic reviewed, it might be concluded that a large number of research articles in midwifery stress the importance of communication in midwifery practice and training. However, there is a lack of research articles focusing on the evaluation of the effectiveness of training programs and different methods used in interventions. Even in research studies where training programs were evaluated, communication skills enhancement is usually measured only as an additional factor in training programs aimed at developing technical skills and knowledge in midwifery.

Although positive effects of communication training programs were reported in the reviewed articles, there was a high level of heterogeneity in the intervention methods, length and outcome measures used within the training programs. Research studies comparing the effectiveness of the different education methods using objective outcome measures, and with good quality methodological background, are needed in this area in order to formulate clear recommendations for practice regarding effective interventions.

\section{Limitation of the study}

Methodological limitations of the review study include the fact that the search process for articles eligible for the review was realized by a single person, posing a risk of subjective bias. In addition, only articles published in English were included in this review, narrowing the scope of the article.

\section{Ethical aspects and conflict of interest}

The author declares no conflict of interests.

\section{References}

Beaubien JM, Baker DP. The use of simulation for training teamwork skills in health care: how low can you go? Quality and Safety in Health Care. 2004;13(Suppl 1):i51-56.

Birch L, Jones N, Doyle PM, Green P, McLaughlin A, Champney C, Williams D, Gibbon K, Taylor K. Obstetric skills drills: evaluation of teaching methods. Nurse Education Today. 2007;27(8):915-922.

Casey A, Wallis A. Effective communication: Principle of Nursing Practice E. Nursing Standard. 2011;25(32):35-37.

Catling C, Hogan R, Fox D, Cummins A, Kelly M, Sheehan A. Simulation workshops with first year midwifery students. Nurse Education in Practice. 2016;17:109-115.

Crofts JF, Bartlett C, Ellis D, Winter C, Donald F, Hunt LP, Draycott TJ. Patient-actor perception of care: a comparison of obstetric emergency training using manikins and patientactors. Quality \& Safety in Health Care. 2008;17(1):20-24

Eccles M, Grimshaw J, Campbell M, Ramsay C. Research designs for studies evaluating the effectiveness of change and improvement strategies. Quality and Safety in Health Care. 2003;12(1):47-52.

Hobgood C, Sherwood G, Frush K, Hollar D, Maynard L, Foster B, Sawning S, Woodyard D, Durham C, Wright M, Taekman J; Interprofessional Patient Safety Education Collaborative. Teamwork training with nursing and medical students: does the method matter? Results of an interinstitutional, interdisciplinary collaboration. Quality and Safety in Health Care. 2010;19(6):e25.

Lin YR, Shiah IS, Chang YC, Lai TJ, Wang KY, Chou KR. Evaluation of an assertiveness training program on nursing and medical students' assertiveness, self-esteem, and interpersonal communication satisfaction. Nurse Education Today. 2004;24(8):656-665.

McDonald G, Jackson D, Wilkes L, Vickers MH. A workbased educational intervention to support the development of personal resilience in nurses and midwives. Nurse Education Today. 2012;32(4):378-384.

McLachlan HL, Forster DA, Collins R, Gunn J, Hegarty K. Identifying and supporting women with psychosocial issues during the postnatal period: evaluating an educational intervention for midwives using a before-and-after survey. Midwifery. 2011;27(5):723-730.

Monod C, Voekt CA, Gisin M, Gisin S, Hoesli IM. Optimization of competency in obstetrical emergencies: a rolefor simulation training. Archives of Gynecology and Obstetrics. 2014;289(4):733-738. 
Parratt JA, Fahy KM, Hastie CR. Midwifery students' evaluation of team-based academic assignments involving peer-marking. Women Birth. 2014;27(1):58-63.

Solomon P, Salfi J. Evaluation of an interprofessional education communication skills initiative. Education for Health (Abingdon). 2011;24(2):616.
Warland J, Smith M. Using online roleplay in undergraduate midwifery education: a case-study. Nurse Education in Practice. 2012;12(5):279-283. 